\title{
A GESTÃO AMBIENTAL INFLUENCIANDO O DESEMPENHO COMPETITIVO DAS EMPRESAS EXPORTADORAS
}

\author{
A. C. R. Costa \\ Graduanda em Tecnologia em Comércio Exterior - CEFET-RN ${ }^{1}$ \\ carolr.costa@yahoo.com.br \\ Gerda L. P. Camelo \\ Professora do Departamento de Gestão, Serviço e Comércio do CEFET-RN \\ gerda@cefetrn.br
}

S. S. Souza ${ }^{1}$

Graduando em Administração - UFRN

savyoss@yahoo.com.br

S. S. Maia ${ }^{1}$

p4pit0@gmail.com

\section{RESUMO}

A existência de uma legislação cada vez mais exigente oriunda de uma crescente preocupação em relação às questões ambientais força as organizações a se preocuparem cada vez mais em atingir e demonstrar um desempenho ambiental correto. No âmbito do comércio exterior, surgem as barreiras ambientais, uma espécie de barreira comercial imposta por países que estabelecem severas exigências, acabando por impedir a entrada de produtos importados em seu território. Com isso, visando garantir a competitividade de seus produtos, os países exportadores adotam padrões de qualidade ambiental, buscando ordenação legal para o uso sustentável de seus recursos naturais através da adequação a normas como a ISO 14.001, responsável pelo auxílio às organizações no processo de iniciar, aprimorar e sustentar o Sistema de Gestão Ambiental. Tais sistemas, por sua vez, são essenciais para uma organização atender às expectativas de desempenho ambiental e assegurar a conformidade com os requerimentos nacionais e/ou internacionais. Com base no exposto, o presente estudo visa analisar a influência da Gestão Ambiental, através da implementação de SGA (Sistemas de Gestão Ambiental), no desempenho competitivo das empresas inseridas no comércio internacional. Para isso, este trabalho utilizou a pesquisa bibliográfica e de campo, assim como também um questionário aberto e semi-estruturado.

Palavras-chave: Questão Ambiental, Competitividade, Cenário Internacional. 


\section{A GESTÃO AMBIENTAL INFLUENCIANDO O DESEMPENHO COMPETITIVO DAS EMPRESAS EXPORTADORAS}

\section{INTRODUÇÃO}

Atualmente, a questão ambiental assume uma grande relevância estando relacionada a problemas ambientais como o aquecimento global, a utilização de recursos naturais não renováveis, a ocupação inadequada e a degradação dos solos agricultáveis, escassez, mau uso e poluição das águas dentre outros. A responsabilidade ambiental vem na tentativa de ajudar na busca por novos paradigmas de produção e consumo por meio de ferramentas que possibilitem a implementação da gestão ambiental.

Seguindo essa tendência, um novo tipo de empresa tem surgido no cenário internacional. Socialmente responsável e preocupada com questões ambientais, estas organizações incluem em seus planejamentos estratégicos questões muito mais abrangentes do que as tradicionais metas econômico-financeiras.

São corporações preocupadas com sua inserção no meio em que operam, buscando levar em conta necessidades e preocupações de todos os seus públicos de interesse - clientes, empregados, comunidades, governo, parceiros, fornecedores, além de visarem a criação de valor ao acionista no longo prazo. Entre outras características, podemos citar a transparência frente a investidores, padrões de governança elevados e a gestão de recursos humanos orientada pela capacitação e satisfação de seus funcionários.

Segundo o modelo ETHOS de responsabilidade ambiental, a empresa deve criar um sistema de gestão que assegure que ela não contribui com a exploração predatória e ilegal do meio ambiente. Deve organizar sua estrutura interna de maneira que o meio ambiente não seja um tema isolado, mas que permeie todas as áreas da empresa, sendo considerado a cada produto, processo ou serviço que a empresa desenvolve ou planeja desenvolver. Um critério importante para uma empresa consciente de sua responsabilidade ambiental é um relacionamento ético e dinâmico com os órgãos de fiscalização, com vistas à melhoria do sistema de proteção ambiental.

\section{SISTEMAS DE GESTÃO AMBIENTAL}

Segundo PHILIPPI \& MAGLIO (2005), o Sistema de Gestão Ambiental é o formato institucional e o conjunto de métodos e procedimentos adotados pela organização, para aplicar sua política ambiental e melhorar o seu desempenho ambiental.

A Gestão Ambiental é uma abordagem sistêmica em que a preocupação ambiental está em todos os aspectos do negócio das organizações. A implementação de sistemas de gestão ambiental é, normalmente, um processo voluntário. Ao optar pela sua implantação, porém, as companhias não estão visando apenas os benefícios financeiros (economia de matériaprima, eficiência na produção e marketing). Estão também estimando os riscos de não gerenciar adequadamente seus aspectos ambientais (acidentes, descumprimento da legislação ambiental, incapacidade de obter crédito bancário e outros investimentos de capitais, e perda de mercados por incapacidade competitiva). 
A aplicação das normas da série ISO 14000 (conjunto de normas de qualidade ambiental), pressupõe que a empresa que se dispõe voluntariamente a aplicá-la atenda a requisitos normatizados como Desempenho Ambiental, Auditoria Ambiental, Rotulagem Ambiental, Ciclo de Vida do Produto e Aspectos Ambientais em Normas e Produtos. A norma tem por objetivo a certificação ambiental de seu processo, reconhecida pelos diversos países signatários da Federação, e respectivos mercados.

Os apelos de natureza comercial para a imagem das empresas, quando da obtenção de certificações, a partir da implantação de sistemas de gestão ambiental, representam um novo instrumento de gestão ambiental direcionado para o setor produtivo, e representarão um elemento enriquecedor das práticas de gestão, com repercussões positivas para a regulação ambiental.

A utilização voluntária de políticas de gestão ambiental poderá, em certa medida, reduzir a pressão e o licenciamento ambiental, uma vez que os órgãos ambientais públicos poderão reconhecer e valorizar os procedimentos adotados pelas empresas privadas e utilizá-los em programas especiais de autocontrole e automonitoramento das empresas.

\section{RESPONSABILIDADE AMBIENTAL EMPRESARIAL}

Segundo CAVALCANTI (2003), uma empresa relaciona-se com o meio ambiente causando impactos de diferentes tipos e intensidades. Dessa maneira, empresas ambientalmente responsáveis devem agir visando a manutenção e melhoria das condições ambientais, minimizando ações próprias potencialmente agressivas ao meio ambiente e disseminando em outras empresas as práticas e conhecimentos adquiridos nesse sentido.

Nos primórdios do ambientalismo empresarial, o principal obstáculo ao engajamento do empresariado na ecoeficiência residia na concepção dominante de que a proteção ambiental e o lucro eram adversários naturais. Supunha-se que o mais adequado gerenciamento ambiental nas empresas, além de reduzir lucros, obrigaria estas a repassar os custos aos consumidores, via aumento de preços. Além disso, o custo da tecnologia ambiental era alto em virtude de não estar nem tão disponível, nem tão aperfeiçoada como hoje.

Com o passar dos anos, entretanto, tornou-se claro que as tecnologias ambientais possuíam um potencial inverso, ou seja, reduziam custos através de uma melhor racionalização dos processos produtivos, particularmente no uso de insumos e com relação ao desperdício. Dessa forma, este movimento representou a primeira mudança cultural de importância no pensamento empresarial quanto às questões ambientais. Desde então, tal modelo vem evoluindo, expandindo-se e adaptando-se cada vez mais à nossa realidade e demandas atuais.

O desenvolvimento sustentável de uma região requer também a seleção de sistemas de produção que atentem para condições ambientais diversificadas, e conseqüentemente, a escolha de tecnologias adequadas a cada um desses sistemas nesses ambientes.

Através da proposição de princípios, de diretrizes e de mecanismos de estruturação, controle e tomada de decisões gerenciais, os Sistemas de Gestão Ambiental promovem o uso, a proteção, a conservação e o monitoramento de recursos naturais e sócio-econômicos 
do espaço rural, tendo sempre em foco as vertentes ecológicas, econômicas e sociais nessas atividades.

Nesse contexto, processos que fomentem a Gestão Ambiental do Espaço Agrário tornamse fortes aliados à implantação correta desses sistemas, uma vez que fornecem um conjunto de atividades de planificação, de prática e de controle do espaço rural que define a política ambiental local, seus objetivos e responsabilidades culminando com a produtividade desejada pelo produtor aliada a minimização de impactos ambientais negativos.

\section{AS EXIGÊNCIAS DO MERCADO INTERNACIONAL}

A fim de aumentar a presença nos mercados internacionais, empresários brasileiros precisam selecionar mercados para a venda, identificar tendências e expectativas dos consumidores e buscar informações sobre a concorrência, avaliando oportunidades e riscos.

Para ter acesso aos benefícios gerados pela conquista de consumidores internacionais, há um caminho a ser percorrido: controle de qualidade dos produtos, criação de embalagens adequadas e qualificação empresarial. É necessário seguir algumas normas internacionais para garantir penetração legal e eficaz no mercado exterior.

Na América Latina, os países que formam o Mercado Comum do Cone Sul (Mercosul, formado por Brasil, Argentina, Chile, Uruguai e Paraguai) criaram o Comitê de Sanidade Vegetal do Cone Sul (Cosave), com o objetivo de harmonizar as normas fitossanitárias utilizadas nesse mercado. Constantemente, são feitos exames de amostras, testes e outras verificações para evitar que pragas e doenças típicas de cada país se espalhem pelo continente. Além disso, as empresas e os produtos devem ter registro no Ministério da Agricultura, Pecuária e do Abastecimento (Mapa) ou na Secretaria da Agricultura do Estado de onde o produto será exportado.

\subsection{Certificados e Organismos Responsáveis pela Anuência do Produto}

O cenário mercadológico internacional sinaliza que existe um movimento de consumidores à procura por alimentos sadios. Cadeias de distribuidores e grandes pontos de vendas, principalmente da Comunidade Européia, levam em consideração o nível de resíduos de agrotóxicos, o respeito ao meio ambiente e as condições de trabalho, higiene e saúde dos envolvidos na produção de alimentos.

Desta forma, os governos de todos os níveis têm reforçado o controle das atividades industriais e aumentado as penalidades por violação das leis e regulamentações ambientais. Penalidades civis e criminais novas e mais sérias são impostas à violação das leis ambientais, principalmente se a violação representa um risco à saúde ou danos de longo prazo aos recursos naturais, como qualidade do solo ou mananciais.

Os empresários passam, então, a ser obrigados a monitorar suas organizações para provar que estão em conformidade com a legislação em vigor, enquanto as agências ambientais reguladoras estão cada vez mais treinadas para identificar o descumprimento dessa legislação. 
Segundo o MAPA, Ministério da Agricultura, Pecuária e Abastecimento, muitos são os certificados e organismos responsáveis pela anuência do produto nas relações comerciais, além de protocolos de exportação, análises fitossanitárias, pragas, doenças e até decisões diplomáticas que barram a entrada dos produtos brasileiros em alguns países. Entre tais certificados e organismos, podemos citar: USDA, HACCP e EUREPGAP, detalhados logo abaixo.

USDA é o acrônimo para United States Department of Agriculture, o departamento de agricultura dos Estados Unidos. Seu objetivo é desenvolver e executar políticas relacionadas à agricultura, apoiar os agricultores e pecuaristas, promover o comércio de bens agrícolas, garantir a segurança alimentar, proteger os recursos naturais, apoiar as comunidades rurais e também garantir que as necessidades do povo estadunidense sejam atendidas.

O HACCP tem como objetivo garantir a produção de alimentos seguros ao consumidor final do mercado interno e externo. O sistema consiste em um conjunto de ações, medidas e procedimentos adotados para caracterizar a padronização de carcaças, dos cortes de carne e também dos processos de produção e controle, incluindo as seguintes etapas:

A. Auditorias: Tem como objetivo avaliar o plano de HACCP e seus registros e procedimentos executados durante os processos de produção.

B. Certificação: certifica que o estabelecimento está em conformidade com normas e padrões nacional e internacional do sistema de qualidade HACCP

A EUREPGAP é um sistema de gestão de qualidade cuja finalidade é assegurar alimentos seguros e sustentáveis para seus clientes. A EUREPGAP criou normativas para os seguintes setores: frutas e vegetais, flores ornamentais, aquacultura e café.

O protocolo EUREPGAP-IFA é baseado na BPA/GAP (Boas Práticas da Agricultura), padrões globais de segurança alimentar e HACCP (Análise de Perigo e Pontos Críticos de Controle). Ele cobre todo o processo de produção agrícola do produto certificado, desde a entrada do animal no processo de produção ou no plantio (origem e pontos de controle das sementes) até o produto final não processado (não cobre o processamento ou abate).

Os princípios do Programa EUREPGAP estão baseados nos seguintes conceitos:

- Segurança Alimentar: se derivam dos princípios do HACCP (Análise de riscos e pontos críticos de controle);

- Proteção Ambiental: designado para minimizar o impacto negativo da produção agrícola no meio ambiente;

- Saúde, Segurança e Bem estar ocupacional: a normativa estabelece um nível global de critérios de saúde e segurança ocupacional nas fazendas, propiciando assim a responsabilidade social;

- Bem estar animal: a normativa estabelece um nível global de critérios de bem estar animal nas fazendas.

\subsection{As Normas da ISO 14000}

A série ISO 14000, conjunto de normas na área de gestão ambiental estabelecida pelo GATT (General Agreement for Tariffs and Trade - Acordo Geral de Tarifas e Comércio), visa padronizar procedimentos e certificar empresas em 140 países visando a redução das 
barreiras tarifárias. A série foi inicialmente elaborada visando o "manejo ambiental”, que significa "o que a organização faz para minimizar os efeitos nocivos ao ambiente causados pelas suas atividades" (ISO, 2000).

Assim sendo, essas normas fomentam a prevenção de processos de contaminações ambientais, uma vez que orientam a organização quanto a sua estrutura, forma de operação e de levantamento, armazenamento, recuperação e disponibilização de dados e resultados (sempre atentando para as necessidades futuras e imediatas de mercado e, conseqüentemente, a satisfação do cliente), entre outras orientações, inserindo a organização no contexto ambiental.

A norma ISO 14001 estabelece as diretrizes básicas para o desenvolvimento de um sistema que gerencie a questão ambiental dentro da empresa, ou seja, um sistema de gestão ambiental e, assim: avalia as conseqüências ambientais das atividades, produtos e serviços da organização; atende a demanda da sociedade; define políticas e objetivos baseados em indicadores ambientais definidos pela organização que podem retratar necessidades desde a redução de emissões de poluentes até a utilização racional dos recursos naturais; implica na redução de custos, na prestação de serviços e em prevenção, sendo aplicada às atividades com potencial de efeito no meio ambiente e a organização como um todo.

Ressalta-se, contudo, que nem as normas ISO 9000 nem aquelas relativas ISO 14000 são padrões de produto. O padrão de manejo do sistema nessas famílias de normas estabelece requerimentos para direcionar a organização para o que ela deva fazer para manejar processos que influenciam a qualidade (ISO 9000) ou processos que influenciam o impacto das atividades da organização no meio ambiente (ISO 14000). A natureza do trabalho desenvolvido na empresa e as suas especificidades em termos de demandas determinam os padrões relevantes do produto que devam ser considerados no contexto das normas ISO (ISO, 2000).

A partir de 1995 passam a ser adotadas pelas empresas privadas a aplicação de normas da série ISO 14000 (CAVALCANTI, 2001). Especialmente as empresas exportadoras, que são fortemente pressionadas pelo mercado globalizados para adotarem o sistema de certificação ambiental, uma vez que as regras de mercado e a competitividade internacional são indutoras destes novos procedimentos.

\section{INFLUÊNCIAS DA GESTÃO AMBIENTAL NA COMPETITIVIDADE DE EMPRESAS EXPORTADORAS NORTE-RIOGRANDENSES}

Os sujeitos da pesquisa foram empresas que comercializam no mercado internacional frutas de destaque na balança comercial do RN sob todos os parâmetros da qualidade ambiental. Os dados coletados referem-se a entrevistas realizadas junto a 02 (duas) empresas de destaque no cenário econômico exportador do estado com ajuda de um questionário.

\subsection{Estudo de Caso de uma Empresa Exportadora de Mamão}

Desde 2003 a empresa possui um volume de exportação considerável e, atualmente, exporta com regularidade para Estados Unidos, Canadá e todos os países europeus, contando com tradings na Europa e Estados Unidos para a comercialização e distribuição de seus produtos. Sua produção, entretanto, não se destina apenas ao mercado 
internacional, mas também ao mercado interno, através da distribuição em redes de supermercados.

Atualmente, visando a expansão de seu mercado, divulga o mamão no mercado internacional e busca atender às exigências dos consumidores no tocante à qualidade do produto. Por este motivo, foi desenvolvido um nicho de mercado para o mamão de qualidade, nos mercados Europeu e Americano. A nova unidade da empresa utiliza em seus equipamentos a mais avançada tecnologia mundial de processamento de frutas.

A empresa é uma das poucas que possuem licença para exportar para o mercado americano. Entre os certificados de qualidade ambiental possuído pela empresa e que representam a responsabilidade com o desenvolvimento sustentável da região, podemos citar a EurepGAP, definida pela comunidade européia.

Segundo dados obtidos através de questionário respondido por funcionários da empresa, dentre os países para onde a empresa exporta, a Inglaterra é o mais exigente quanto à questão ambiental, muito além do que prevê a legislação brasileira. O país considera em sua avaliação impactos sobre a água, solo e ar, decorrentes da exploração agrícola.

Em conformidade às exigências externas, os principais procedimentos de avaliação do produto utilizados pela empresa são procedimentos internos de avaliação e classificação do produto. A empresa também possui um Sistema de Gestão da Qualidade, assim como o Sistema de Gestão Integrado, que se baseia nas normas ISO 9001 e 14001 (normas das séries ISO 9000 e ISO 14000), visando a qualidade para o cliente e a minimização de impactos ambientais, e o Selo do IBD (Instituto BioDinâmico), que atesta o compromisso com um produto orgânico de qualidade. A certificação em APPCC / HACCP - Análise de Perigos e Pontos Críticos de Controle, garante também a segurança alimentar dos produtos.

A empresa trata a questão ambiental como tema importante em sua estrutura organizacional e a inclui no planejamento estratégico, produzindo estudos de impactos ambientais e focando sua ação preventiva nos processos que oferecem dano potencial à saúde e risco à segurança de seus empregados. Através de estudos, conhece e desenvolve ações para prevenir os principais impactos causados por seus processos e produtos ou serviços e realiza regularmente atividades de controle e monitoramento, procurando reduzir o consumo de energia, água, produtos tóxicos e matérias-primas, e implantar processos de destinação adequada de resíduos. A empresa também tem investido na atualização do seu padrão tecnológico visando a redução e/ou substituição de recursos de entrada e a reutilização de resíduos (pela própria empresa ou por terceiros).

Assim, através da busca pela melhoria contínua da qualidade de produtos e processos, a empresa atua dentro dos limites legais para a melhoria do meio ambiente e qualidade de vida do ser humano, através da redução de emissão de poluentes. Em 2006, graças a investimentos na qualidade do produto, as exportações de mamão cresceram de $20 \%$ a $25 \%$, com a entrada, em 2007, no mercado norte-americano, cujo potencial de consumo é de aproximadamente 70 mil toneladas/ano.

Localizada em Natal, capital do Estado do Rio Grande do Norte, a empresa atende aos mercados Americano e Europeu sem maiores custos logísticos graças à privilegiada localização geográfica. A Organização fornece todo o conhecimento necessário para a produção do mamão papaya, além de oferecer a estrutura física necessária para atender à crescente demanda do mercado externo e interno. 
A empresa possui um programa social caracterizado por uma parceria com os trabalhadores sem terra da região, garantindo às famílias renda e melhoria da qualidade de vida. A empresa trabalha divulgando a produção dos novos empresários visando garantir a compra das frutas produzidas pelos trabalhadores, mostrando iniciativa social e promovendo, assim, o desenvolvimento da região.

\subsection{Estudo de Caso de uma Empresa Exportadora de Melancia e Melão}

Fundada em 1995, a empresa é de capital nacional e situa-se na divisa dos estados do Rio Grande do Norte e Ceará. A empresa possui uma produção diversificada, contando com 1.200 colaboradores nos períodos de safra e, em pouco mais de uma década, consolidou seu nome no agronegócio graças a investimentos em novas tecnologias, pesquisa constante e respeito ao meio ambiente.

Visando intensificar a qualidade de produto e atender às exigências externas, são realizados procedimentos que vão desde a qualidade da produção no campo até a embalagem do produto final. Para uma melhor avaliação das frutas, é realizada também uma análise de peso, aparência, sabor e quantidade de açúcar. Somado a essas ações, a empresa procura diversificar também a variedades, melhorar a logística e o resfriamento das frutas.

Segundo dados obtidos através de questionário respondido por seus funcionários, a empresa cumpre os parâmetros e requisitos pela legislação nacional, desenvolvendo programas internos de melhoramento ambiental, prioriza políticas preventivas e possui área ou comitê responsável pelo meio ambiente e desenvolve ações de educação e treinamento de empregados sobre a temática ambiental, assim como atividades de educação ambiental focadas no público interno, disponibilizando informações e promovendo discussões.

Possui também sistema de gestão ambiental incluindo identificação de riscos, plano de ação, alocação de recursos e treinamento de empregados, desenvolvendo parcerias com fornecedores em busca da melhoria de seus processos de gestão ambiental. Participa da destinação final do produto e processos pós-consumo e tem procurado reduzir o consumo de energia, água, produtos tóxicos e matérias-primas, e implantar processos de destinação adequada de resíduos, além de investir na atualização do seu padrão tecnológico visando a redução e/ou substituição de recursos de entrada e a reutilização de resíduos (pela própria empresa ou por terceiros).

Localizada no semi-árido do Nordeste do Brasil, um quarto de sua área destina-se exclusivamente ao cultivo de diferentes variedades de melões e melancias. A localização privilegiada permite proximidade com os principais centros consumidores do mundo, diminuindo os custos logísticos e garantindo mais competitividade à empresa.

Segundo dados da empresa, na safra de 2003/2004 foram exportadas 32 mil toneladas de fruta, concentrando-se principalmente nos mercados inglês, holandês, belga e alemão. A empresa busca constantemente ampliar seus mercados e, na safra atual, além dos mercados já abastecidos, as exportações estão sendo expandidas para a Suécia, Itália, Estados Unidos e Tailândia. 
Sua capacidade anual de produção é de 1.300 mil e trezentos hectares por ano, entre melão e melancia. A empresa gera em torno de 1.500 empregos diretos, gerando renda para o estado e contribuindo de forma significativa para o maior aproveitamento possível da diversidade fruticultora do estado.

\section{CONSIDERAÇÕES FINAIS}

Como conseqüência para as empresas que investem na questão ambiental, podemos citar a melhoria da imagem institucional, o acesso seguro ao mercado externo e o alto compromisso de pessoal, melhoria nas relações de trabalho e criatividade para novos desafios.

As empresas que investem em atividades de responsabilidade ambiental conseguem agregar valores à marca de seus produtos posicionando-os melhor no mercado, refletindo positivamente no conjunto de suas relações com órgãos governamentais, comunidade, grupos ambientalistas e com a mídia que a cada dia vem debatendo a importância em proteger o meio ambiente.

A crescente abertura comercial dos países para o exterior obriga as empresas a sobreviverem em um mercado de competição global. Para aqueles que exportam ou pretendem iniciar atividades de comércio exterior, órgãos internacionais, ou até mesmo países importadores obrigam que os produtos ou serviços ofertados estejam em conformidade com os mais altos padrões de qualidade técnica e ambiental. Somente aqueles que melhor se adequarem a esses padrões conseguem obter os benefícios advindos do comércio internacional.

Assim, as empresas que difundem a gestão ambiental tendem a buscar e atrair mão-de-obra qualificada para o desenvolvimento de seus negócios. As empresas que investem em ações sócias ambientais são mais admiradas também pelos empregados em potencial. Também é possível que as práticas de responsabilidade sócio ambiental do dia-a-dia aplicadas internamente na empresa sirvam como elemento motivador para que os colaboradores sintam-se integrados a contribuir positivamente não só ao meio ambiente, mas também a própria empresa na solução e busca de novos desafios melhorando o seu desempenho.

No caso das empresas norte-riograndenses, foram realizados procedimentos de avaliação do produto em conformidade às exigências externas, como a implantação de Sistemas de Gestão da Qualidade, que trouxeram às empresas grandes benefícios como a melhoria da imagem da empresa no cenário internacional, a redução do desperdício de matéria-prima e eficiência na produção, entre outros ganhos já especificados anteriormente.

\section{REFERÊNCIAS}

CAVALCANTI, Clóvis. Desenvolvimento e natureza: estudos para uma sociedade sustentável. 4.ed. Recife: Fundação Joaquim Nabuco/Cortez Editora, 2003.

INSTITUTO ETHOS DE EMPRESAS E RESPONSABILIDADE SOCIAL. Disponível em: <http://www.ethos.org.br>. Acesso em: 26 mai. 2007. 
Meio Ambiente, Desenvolvimento Sustentável e Políticas Públicas/ Clóvis Cavalcanti (Org) - $3^{\mathrm{a}}$ ed. - São Paulo: Cortez: Recife: Fundação Joaquim Nabuco, 2001.

PHILIP, Arlindo Júnior e MAGLIO, Ivan Carlos. Políticas e Gestão Ambiental: Conceitos e Instrumentos. In: Educação Ambiental e Sustentabilidade/ Arlindo Philippi Jr., Maria Cecília Focesi Pelocioni, editores - Barueri, SP: Manole, 2005. 